\title{
Effects of strand length and layer structure on some properties of strandboard made from bamboo
}

\author{
Ihak Sumardi • Yoichi Kojima • Shigehiko Suzuki
}

Key words: Bamboo - Strand length - Layer structure · Alignment angle - Bending properties

Article type: Original article

I. Sumardi · Y. Kojima • S. Suzuki $(\bowtie)$

Wood Science Laboratory, Faculty of Agriculture, Shizuoka University, 836-Ohya, Shizuoka 422-8529, Japan

Tel: +81-54-238-4854; Fax: +81-54-237-3128

E-mail: s-suzuki@agr.shizuoka.ac.jp

Corresponding author : Prof. Shigehiko SUZUKI

Wood Science Laboratory, Faculty of Agriculture, Shizuoka

University, 836-Ohya, Shizuoka, 422-8529 Japan

Tel. +81-54-238-4854; Fax +81-54-237-3128

E-mail: s-suzuki@agr.shizuoka.ac.jp 


\section{Abstract}

Strandboard panels were experimentally produced from moso bamboo (Phyllostachys pubescens) using various strand lengths and layer structures to evaluate the effects of manufacturing parameters on panel properties. The strandboard was fabricated in a laboratory using diphenylmethane diisocyanate (MDI) resin and laboratory-made strands of four lengths and four different structures. Strand alignment distributions and concentration parameter $(\mathrm{k})$ values were greatly affected by strand length. A linear correlation was found between the value of $k$ and the modulus of rupture (MOR), with coefficients of 0.81 and 0.93 for unidirectional boards and three-layer boards, respectively. This correlation may be used to predict the strength properties of boards. Bending properties were significantly affected by both the strand length and the layer structure of the bamboo strandboard tested. Elasticity data from unidirectional boards and random boards can be used to predict the elastic properties of three-layer boards. The linear expansion (LE) of the random boards increased with decreasing strand length. The difficulty in mat forming and resin distribution for longer strands could cause deviation in modulus of elasticity (MOE) and LE, especially in strand lengths around 80 $\mathrm{mm}$.

Key words: Bamboo · Strand length · Layer structure · Alignment angle • Bending properties 


\section{Introduction}

In recent years, an increase in housing construction has resulted in a high demand for lumber products. On the other hand, the quantity and quality of wood resources from forests have declined. Consequently, there is great interest in using non-wood resources as alternative raw materials. Bamboo is a non-wood lignocellulosic material that has potential for composite panels such as particleboard and fiberboard. Several papers have reported the utilization of bamboo in various composite panels such as plywood ${ }^{1}$, zephyr-board ${ }^{2}$, particleboard, ${ }^{3,4}$ fiberboard, ${ }^{5-7}$ waferboard, ${ }^{8}$ and oriented strandboard. ${ }^{9}$

Understanding the basic properties of bamboo is important when considering it as a raw material, especially for oriented strandboard (OSB). The properties of strandboard are strongly influenced by layer-structure, density, strand-length, adhesive, and the aligned angle of strands. Previous studies on wood have reported the effects of layer-structure, strand length, and linear expansion of raw material. ${ }^{10-13}$ Similar information on bamboo as a raw material is limited.

Some work has been done relating board density, resin content, and bending strength on bamboo strandboard manufactured using phenol formaldehyde (PF) as a binder. ${ }^{14}$ Positive correlations were found between the density, resin content (RC) and bending strength of the panels. However, internal bond (IB) strength was not satisfactory with PF resin. Diphenylmethane diisocyanate (MDI) was used as an alternative binder to improve board properties. Rool $^{15}$ reported that MDI was more suitable for cellulose material, spread out spontaneously on a wood surface, and has self-activated distribution characteristics superior to those of PF resin. 
Because information on bamboo to be used for structural panels is very limited, further studies on OSB with bamboo as raw material are necessary, especially for strand length and layer structure as basic properties of OSB from bamboo. The objective of this study was to determine the effect of strand length and layer structure on some panel properties of strandboard made from bamboo.

\section{Materials and methods}

\section{Board fabrication}

Moso bamboo (Phyllostachys pubescens) poles were collected from the Shizuoka University bamboo plantation. Each bamboo pole was cut from its base to a height of approximately $8 \mathrm{~m}$. Strands were produced using a laboratory ring-type flaker. Target strand dimensions were $20,40,60$, and $80 \mathrm{~mm}$ long, $0.5 \mathrm{~mm}$ thick, and 5-20 mm wide. Their actual dimensions, determined from 100 strands, were 20.4, 41.1, 58.4, and $73.8 \mathrm{~mm}$ long, 0.45-0.61 mm thick and 7.8 $-10.6 \mathrm{~mm}$ wide. Strands were screened on a 10-mesh sieve before being oven-dried at $60{ }^{\circ} \mathrm{C}$ to a moisture content of less than $3 \%$.

Strandboards with dimensions $370 \times 370 \times 12 \mathrm{~mm}$ and $0.65 \mathrm{~g} / \mathrm{cm}^{3}$ in density were manufactured. Six percent of a commercial liquid MDI (M-200, Mitsui Chemicals Polyurethanes, Inc.) resin content was applied to strands using a pressurized spray gun in a box-type blender. No waxes or other additives were used. Hand-formed mats were pressed for $10 \mathrm{~min}$ at a temperature of $180{ }^{\circ} \mathrm{C}$ using a maximum pressure of $2.5 \mathrm{MPa}$. No surface sanding was performed. Four types of board were fabricated with different layer-structures: randomly oriented homogenous board (RAND), uni-directionally oriented homogenous 
board (UNID), three-layered OSB with a cross-oriented core layer (3LYC), and threelayered OSB with a random core (3LYR). The UNID-boards were produced at ten combinations of three parameters, which were strand length, plate spacing, and free fall distance. The RAND- and 3LYC-boards were produced at four different strand lengths, whereas 3LYR boards were made only at strand length of $40 \mathrm{~mm}$ for comparison. A set of thin plates with $20-\mathrm{mm}$ spacing was used to orient strands during UNID-, 3LYC-, and 3LYR-board mat forming. The layer structure of 3LYR-board was based on the oven-dried weight, and the face-to-core-to-face ratio was 25:50:25. A random board of $40 \mathrm{~mm}$ strand length was used as an experimental control. Four panels were produced for each strand length and each type of layer structure.

Four strand lengths $(20,40,60$, and $80 \mathrm{~mm})$ were used to determine the strand alignment angle distribution of bamboo. Photographs of strands were recorded as digital image data for measuring orientation angle, and the deviations between orientation and strand length direction angles were determined using 1,000 strands oriented at a $20-\mathrm{mm}$ free-fall distance (FFD) and with a 20 -mm plate spacing (PS) as shown in Fig.1.

\section{Board evaluation}

Prior to the bending test, all boards were conditioned at a relative humidity of $65 \%$ and a temperature of $25{ }^{\circ} \mathrm{C}$ for at least 2 weeks. The bending strength test was conducted in accordance with the Japanese Industrial Standard (JIS) for particleboard. ${ }^{16}$ Eight trials were performed for each type of sample to measure modulus of elasticity (MOE) and modulus of rupture (MOR). The plate shear modulus (Gp) was determined by the edgewise vibration 
method using a Fast Fourier Transform analyzer and a specimen with dimensions of $300 \mathrm{x}$ $300 \mathrm{~mm}$. From the peak frequency of the tapping tone, Gp was calculated as follows. ${ }^{17}$

$G p=\pi^{2} \mathrm{~L}^{4} \rho f^{2} /\left(12 h^{2}\right)$

where $\mathrm{L}, \rho, h, f$, and $\pi$ denote the length $(300 \mathrm{~mm})$, density, and thickness $(12 \mathrm{~mm})$ of the specimen, the peak frequency, and the circular constant (3.14), respectively.

Dimensional stability in plane direction was evaluated by measuring linear expansion (LE). Two specimens with dimensions of $300 \times 50 \mathrm{~mm}$ were used based on initial measurements taken after boards were dried at $60{ }^{\circ} \mathrm{C}$ for $22 \mathrm{~h}$. Changes in length were regularly measured during treatment under humid conditions of $40{ }^{\circ} \mathrm{C}$ and $90 \% \mathrm{RH}$ for $150 \mathrm{~h}$, followed by dry conditions of $60^{\circ} \mathrm{C}$ for $150 \mathrm{~h}$, using a dial gauge comparator at an accuracy of $0.01 \mathrm{~mm} .^{18}$

\section{Results and discussion}

Angle distribution

Characteristic of angle distribution is basic information that influences the properties of strandboard. Strand length, FFD and plate spacing are factors that affect strand angle distribution.

Figure 2 shows some typical angle distributions for bamboo strands under identical conditions (FFD and PS $20 \mathrm{~mm}$ ) for UNID-board. The distribution shows that the sharpness of curves increases gradually with increasing strand length. Based on the data on strand alignment angle, curve fitting can be performed using a modified von Mises distribution function (Eq. 2), ${ }^{14,19}$ which is defined as follows: 


$$
f(\mathrm{x}, \mathrm{k})=\frac{1}{\pi \mathrm{I}_{0}(\mathrm{k})} \exp (\mathrm{k} \cos 2 \mathrm{x})
$$

where $\mathrm{x}, \mathrm{k}$, and $\mathrm{I}_{0}$ are the angle defined between $-\pi / 2$ and $\pi / 2$, the concentration parameter, and a modified Bessel function of the first kind and order zero, respectively. The concentration parameter $(\mathrm{k})$ value was obtained by the least squares method. Those values corresponded to the shape of the curve.

Figure 3 illustrates the relationships between strand length and the $\mathrm{k}$ value. The value of $\mathrm{k}$ increased with increasing strand length, and it increased rapidly when strand length increased from 20 to $60 \mathrm{~mm}$. Theoretically, the value of $\mathrm{k}$ should increase exponentially with increasing strand length. Regarding the difficulty in uniform mat forming with longer strands, deviation was observed between the theoretical and actual values especially for a strand length of $80 \mathrm{~mm}$ under the forming condition of this experiment.

The value of concentration parameter $(\mathrm{k})$ is a measure of variance of the angle in the von Mises distribution function. ${ }^{20}$ This is a good indicator for estimation of the curve of the standard distribution angle for the shape of the curve. In addition, this may be used to predict the strength properties of the panels. As illustrated in Fig. 4, we found a linear relationship between $\mathrm{k}$ value and MOR, which was a mean of eight measurements, with coefficient values of 0.81 and 0.93 for UNID- and 3LYC-boards, respectively. The value of MOR increased linearly with increasing value of $k$, and MOR of UNID-board was higher than that of 3LYC-board. Similar to the trend in MOR, a linear relationship was also found between $\mathrm{k}$ and MOE with coefficient values of 0.85 and 0.94 for UNID- and 3LYC-boards, respectively. 


\section{Effect of strand length}

The effect of strand length on bending strength is illustrated in Fig. 5, where the strands were oriented under FFD of $20 \mathrm{~mm}$ and PS of $20 \mathrm{~mm}$. The value of MOR increased with increasing strand length. In the parallel direction (Pr in Fig.5), MOR increased greatly among strand lengths of 20 to $40 \mathrm{~mm}$, and increased slightly beyond this range. Averaged MORs of UNID-board for strand lengths of $20,40,60$, and $80 \mathrm{~mm}$ in the parallel direction reached 46, 70, 83, and $93 \mathrm{MPa}$, respectively, and were relatively constant in the perpendicular direction. These results showed that longer strands can give a high MOR because of effective contributions of the longitudinal properties of the bamboo itself to the board properties especially in UNID-board. On the other hand, the increasing MOR values for RAND- and 3LYC-boards were not as high as those for UNID-board.

The higher MOR values of the panels manufactured using longer strands were also supported by the curve shape of longer strand alignment in terms of angle distribution as illustrated in Fig. 2. This showed that the frequency distribution of strands 60 and $80 \mathrm{~mm}$ long was narrower than that of 20 and $40 \mathrm{~mm}$ long; therefore, it affected mechanical properties especially in the parallel direction.

Figure 6 shows effects of the manufacture parameters on MOE. Strength ratio could be an indicator of board strand alignment and layer structure. The MOE ratios at strand lengths of $40 \mathrm{~mm}$ in the parallel direction were 3.8 and 1.7 times for the perpendicular direction of UNID- and RAND-boards, respectively. The ratios for 3LYC- board were 2.5 and 1.5 for the cross-oriented direction of 3LYC- and RAND-boards, respectively. These values approximated those measurements of Douglas fir strands. ${ }^{11}$ 
Furthermore, the MOE of 3LYC-board can be calculated using two MOEs from the parallel and perpendicular directions of UNID-board as elastic constants for each layer of 3LYC-board in Fig. 6. The calculation used the weight ratio of each layer (25:50:25) as the thickness ratio of each fabricated board. The results indicated good estimation of MOEpredicted in the perpendicular direction and in the parallel direction only for strand lengths of 20 and $40 \mathrm{~mm}$. Some deviations between the theoretical and actual values at strand lengths of 60 and $80 \mathrm{~mm}$ were observed in the parallel direction. It appeared that inhomogeneous resin distribution on longer strands resulted in some problems during mat forming; this influenced the accuracy of prediction of MOE values of the panels.

MOE-predicted of 3LYR-board at a strand length of $40 \mathrm{~mm}$ can be calculated using two MOEs from UNID- and RAND-boards as elastic constants for each layer of 3LYRboard. The results show that the ratios of predicted to actual values were 99 and $101 \%$ for parallel and perpendicular directions, respectively. They indicated that elastic data from UNID- and RAND-boards can be used to predict elastic properties of three-layered boards with a strand length of $40 \mathrm{~mm}$.

\section{Effect of layer-structure}

The plate shear modulus $(\mathrm{Gp})$ is a modulus of rigidity related to the performance of a board when used as wall sheathing. The Gp was affected by layer structure and strand length. The values of RAND-board for strand length of $20,40,60$, and $80 \mathrm{~mm}$ were 1.37, 1.50, 1.53, and 1.65 GPa, respectively, and for UNID-, 3LYR-, and 3LYC-boards for a strand length of $40 \mathrm{~mm}$ were $1.21,1.33$, and $1.24 \mathrm{GPa}$, respectively. The values indicated that random board with strand lengths of $40 \mathrm{~mm}$ or more yielded fairly good shear modulus of OSB 
(ca.1.5 GPa). Although these values were slightly lower than those of sugi strands, ${ }^{12}$ bamboo could exhibit fairly good performance.

Figure 7 shows the effect of layer structure on the MOR of strandboard in parallel and perpendicular directions for a strand length of $40 \mathrm{~mm}$. In the parallel direction, MOR decreased in order from UNID-, 3LYR-, 3LYC-, and RAND-boards. In contrast, for the perpendicular direction, MORs increased from UNID-, 3LYR-, 3LYC-, to RAND-boards. Furthermore, Fig. 7 shows that the decrease in MOR in the parallel direction could be comparable to the increase of MOR in the perpendicular direction. Apparently, contributions of the longitudinal properties of the bamboo shifted gradually from the aligned direction to the cross direction from UNID- to RAND-boards.

\section{Linear Expansion}

Stability in the longitudinal direction is an important property in the use of strandboard. This property was investigated by a linear expansion (LE) test under various conditions of strand length. Figure 8 shows that LE of the random board (RAND) was affected by strand length. These results were for samples after they had been subjected to a humidity test at 40 ${ }^{\circ} \mathrm{C}$ and $90 \% \mathrm{RH}$ for $150 \mathrm{~h}$, followed by a drying test at $60{ }^{\circ} \mathrm{C}$ for $150 \mathrm{~h}$. During the first 50 $\mathrm{h}$, LE increased rapidly; it almost leveled off after $150 \mathrm{~h}$, producing values of $0.28,0.24$, and $0.20 \%$ for strand lengths of 20,40 , and $60 \mathrm{~mm}$, respectively. In the drying stage, LE values became negative.

In this paper, total LE (dLE) and total moisture content change (dMC) were measured from humid and dry conditions for $150 \mathrm{~h}$ and $300 \mathrm{~h}$. The value of dLE decreased from 0.32 to $0.23 \%$ when strand length increased from 20 to $60 \mathrm{~mm}$ (Table 1). Linear 
expansion per unit moisture content change (LE/MC) decreased from 0.028 to $0.020 \% / \%$ within the same range. These values were lower than the values reported for strandboard made from Japanese cedar ${ }^{21}$ and particle board. ${ }^{22}$ The dMC of samples examined here was lower than that of bamboo strandboard with PF as a binder. ${ }^{14}$ The MC of MDI resin-board was lower than that of PF resin board at the $90 \% \mathrm{RH}$ exposure level. ${ }^{22}$ In contrast, the LE of strand lengths near $80 \mathrm{~mm}$ was higher than that of shorter strands (40 and $60 \mathrm{~mm})$. This may be caused by inhomogeneous blending of adhesive and difficulty in mat forming with longer strands.

\section{Conclusions}

We investigated the influence of strand length and layer structure on mechanical properties of bamboo strandboard. Strand alignment distribution and $\mathrm{k}$ values depend strongly on the length of the strand formed. The von Mises distribution function can be used to predict bamboo strand distribution. A linear correlation between $\mathrm{k}$ values and MORs was revealed, which may be used to predict the strength properties of boards. Bending properties were strongly affected by both strand length and layer structure of the bamboo strandboard tested in this experiment. Elasticity data from UNID- and RAND-boards can be used to predict the elastic properties of 3LYC- and 3LYR-boards. The LE increased with decreasing strand length, and the LE/MC ranged from 0.020 to $0.028 \% / \%$. These values were comparable to or lower than those for commercial boards. The difficulty in mat forming and resin distribution for longer strands was evident in the deviation results for MOE-predicted and LE, especially at a strand length of $80 \mathrm{~mm}$. 


\section{Acknowledgments}

We thank Professor Dr. Sobue and Mr. Ikeda, Shizuoka University, for their valuable suggestions throughout the course of this study. 


\section{References}

1. Chen GH (1985) Bamboo plywood. A new product of structural material with high strength properties. Proceedings of the 2nd International Bamboo Workshop, Hangzhou, China, pp 337-338

2. Nugroho N, Ando N (2000) Development of structural composite product made from bamboo I. Fundamental properties of bamboo zephyr board. J Wood Sci 46(1):6874

3. Zhang M, Kawai K, Yusuf S, Imamura Y, Sasaki H (1997) Manufacture of wood composite using lignocellulosic materials and their properties III. Properties of bamboo particleboards and dimensional stability improvement using a steaminjection press (in Japanese). Mokuzai Gakkaishi 43(4):318-326

4. Sakuno T, Han KS (2002) Manufacture and properties of boards made from fresh mosochiku bamboo. Proceedings of the International Conference on Forest Products, Daejeon, Korea, pp 325-330

5. Xu Y, Zhang Y, Wang W (2001) Study on manufacturing technology of medium density fiberboard from bamboo. Proceedings of the Utilization of Agricultural and Forestry Residues, Nanjing, China, pp 117-123

6. Matsumoto K, Yamauchi H, Yamada M, Taki K, Yoshida H (2001) Manufacture and properties of fiberboard made from moso bamboo (in Japanese). Mokuzai Gakkaishi 47(2):111-119

7. Kawai S, Ohmori Y, Han GP, Adachi K, Kiyooka T (2001) A trial of manufacturing high-strength bamboo fiber composites. Proceedings of the Utilization of Agricultural and Forestry Residues, Nanjing, China, pp 124-129 
8. Zhang HJ (2001) A new structural panel composite. Bamboo-based waferboard. Proceedings of the Utilization of Agricultural and Forestry Residues, Nanjing, China, pp 204-209

9. Lee AWC, Bai X, Peralta PN (1996) Physical and mechanical properties of strand board made from moso bamboo. Forest Prod J 46(11/12): 84-88

10. Kajita H (1987) Oriented particleboard with sugi thinning (Cryptomeria japonica) I. Effects of degree of particle alignment and board density on physical and mechanical properties. Mokuzai Gakkaishi 33(11):865-871

11. Canadido LS, Saito F, Suzuki S (1990) Influence of strand thickness and board density on the orthotropic properties of oriented strandboard. Mokuzai Gakkaishi 36(8):632-636

12. Suzuki S, Takeda K (2000) Production and properties of Japanese oriented strand board I. Effect of strand length and orientation on strength properties of sugi oriented strand board. J Wood Sci 46(4):289-295

13. Wu Q, Suchsland O (1996) Linear expansion and its relationship to moisture content change for commercial oriented strandboards. Forest Prod J 46(11/12):79-83

14. Sumardi I, Suzuki S, Ono K (2006) Some important properties of strandboard manufactured from bamboo. Forest Prod J 56(6):59-63

15. Roll H (1990) Distribution of MDI on particles and in particleboard. Proceedings of $1^{\text {st }}$ European Panel Product Symposium, pp 250-257

16. Japanese Industrial Standard (1994) Particleboards, JIS A 5908

17. Dong Y, Nakao T, Chiaki T, Takahashi A, Nishino Y (1992) Evaluation of the characteristics of wood based panels by the in-and out of-planes vibration technique (in Japanese). Mokuzai Gakkaishi 38(7):678-686 
18. American Society for Testing and Materials (1988) Standard test methods for evaluating the properties of wood-base fiber and particle panel materials. ASTM D 1037-177, ASTM, West Conshohocken, PA

19. Harris RA, Johnson JA (1982) Characteristic of flake orientation in flake board by von Mises probability distribution function. Wood Fiber Sci 14(4):254-266

20. Shaler SM (1991) Comparing two measures of flake alignment. Wood Sci and Tech 26:53-61

21. Sekino N, Suematsu A, Fujimoto Y, Kitani Y, Wang Q (2000) Effect of manufacturing parameters on the linear expansion of densified wood composite panels I. Effect of element size and press temperature (in Japanese). Mokuzai Gakkaishi 46(4): 334-341

22. Suematsu A, Sekino N, Fujimoto Y, Kitani Y, Wang Q (2001) Effects of manufacturing parameters on the linear expansion of densified wood composite panels II. Effect of density, resin type and resin content on linear expansion of particle board (in Japanese). Mokuzai Gakkaishi 47(2):129-137 


\section{FIGURE CAPTIONS}

Fig. 1. Plate spacing (A) and free-fall distance (B) of the orienter.

Fig. 2. Effect of strand length on strand angle distribution for unidirectional boards.

Fig. 3. Effect of strand length on concentration parameter $(\mathrm{k})$ values for unidirectional boards.

Fig. 4. Effect of $\mathrm{k}$ values on modulus of rapture (MOR) of UNID- and 3LYC-boards. UNID: unidirectionally oriented homogenous board, 3LYC: three-layer board with a crossoriented core layer, $\mathrm{R}^{2}$ : coefficient determination.

Fig. 5. Effect of strand length on MOR. RAND: randomly oriented homogenous board, Pr: parallel direction, Pp: perpendicular direction. Other symbols were referred to the caption of Fig. 4.

Fig. 6. Effect of strand length on modulus of elasticity (MOE). Dotted lines represent estimated MOE of 3LYC-board using MOE of UNID-board. Other symbols were referred to the caption of Fig. 4 and Fig. 5.

Fig. 7. Effect of layer-structure on MOR at a strand length of $40 \mathrm{~mm}$, FFD of $20 \mathrm{~mm}$, and PS of $20 \mathrm{~mm}$. Other symbols were referred to the caption of Fig. 4 and Fig. 5.

Fig. 8. Effect of strand length on linear expansion (LE) of random board under humid conditions followed by dry conditions 


\section{TABLE}

Table 1 Linear expansion (LE) and LE per unit moisture content change (LE/MC) for humid and dry conditions.

\begin{tabular}{lcccc}
\hline \hline Board type & $\begin{array}{c}\text { Strand } \\
(\mathrm{mm})\end{array}$ & $\begin{array}{c}\mathrm{dMC} \\
\%\end{array}$ & $\begin{array}{c}\mathrm{dLE} \\
\%\end{array}$ & $\begin{array}{c}\text { LE/MC } \\
\% / \%\end{array}$ \\
\hline RAND & 20 & 11.4 & 0.32 & 0.028 \\
RAND & 40 & 11.2 & 0.28 & 0.025 \\
RAND & 60 & 11.5 & 0.23 & 0.020 \\
RAND & 80 & 10.5 & 0.28 & 0.026 \\
\hline \hline
\end{tabular}

dMC: total MC change, dLE: total LE change. 


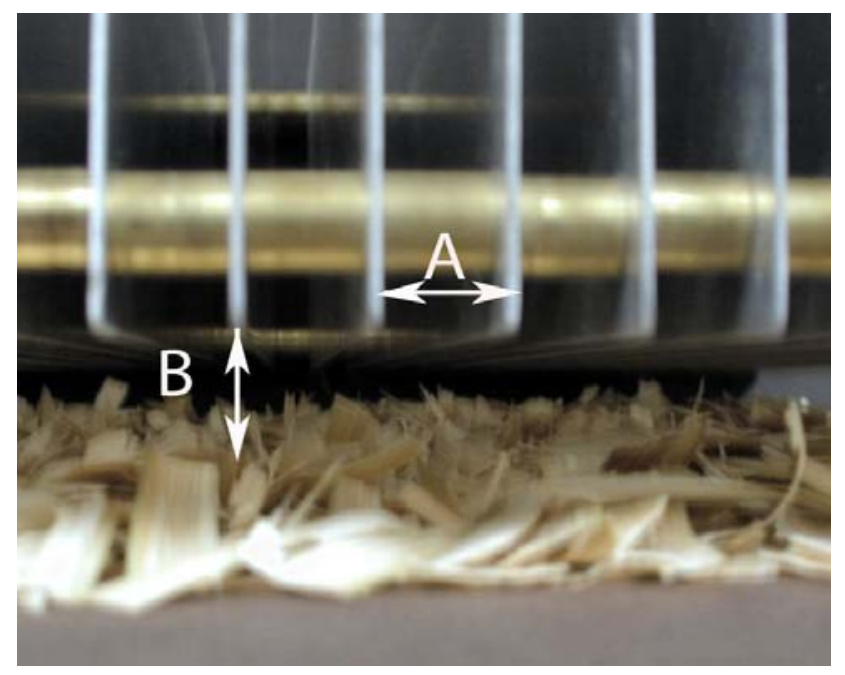




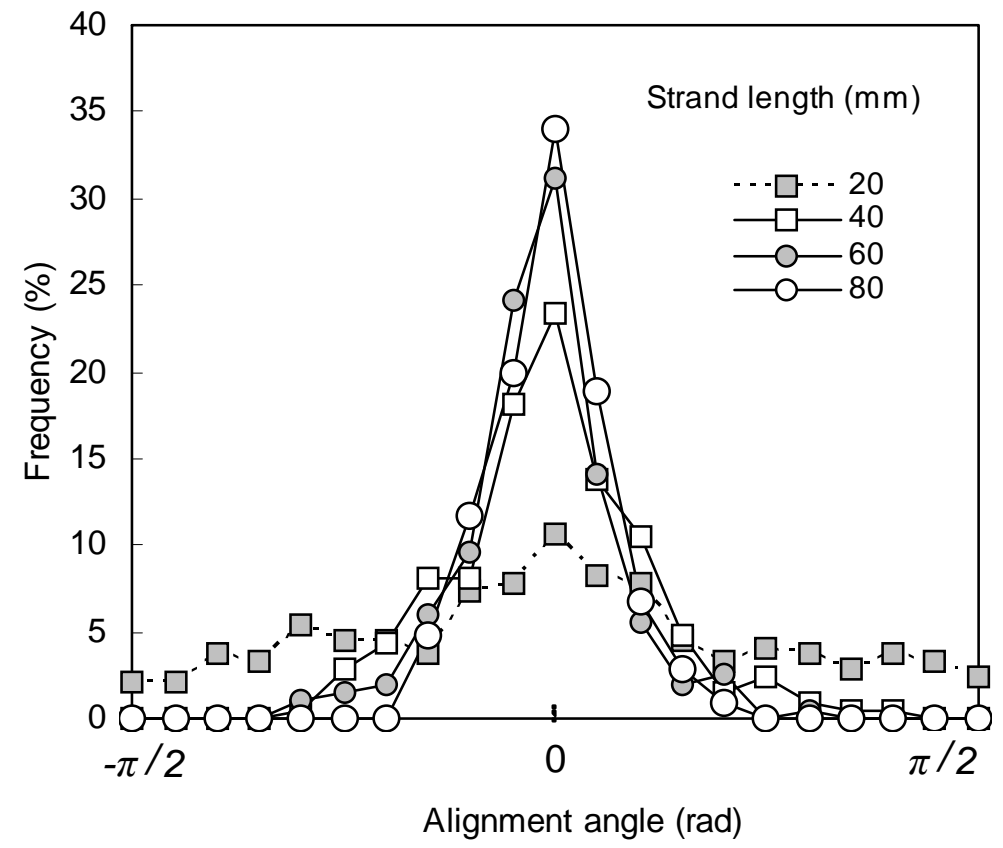




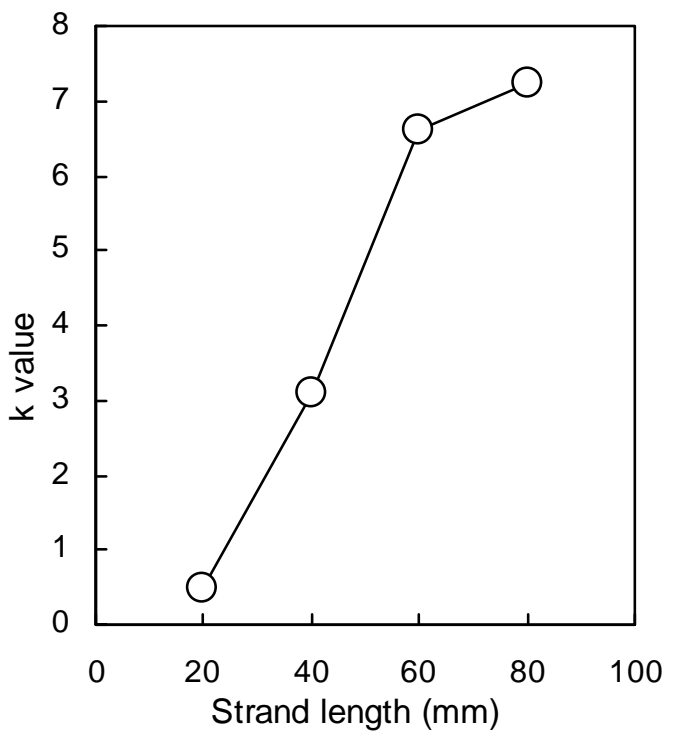




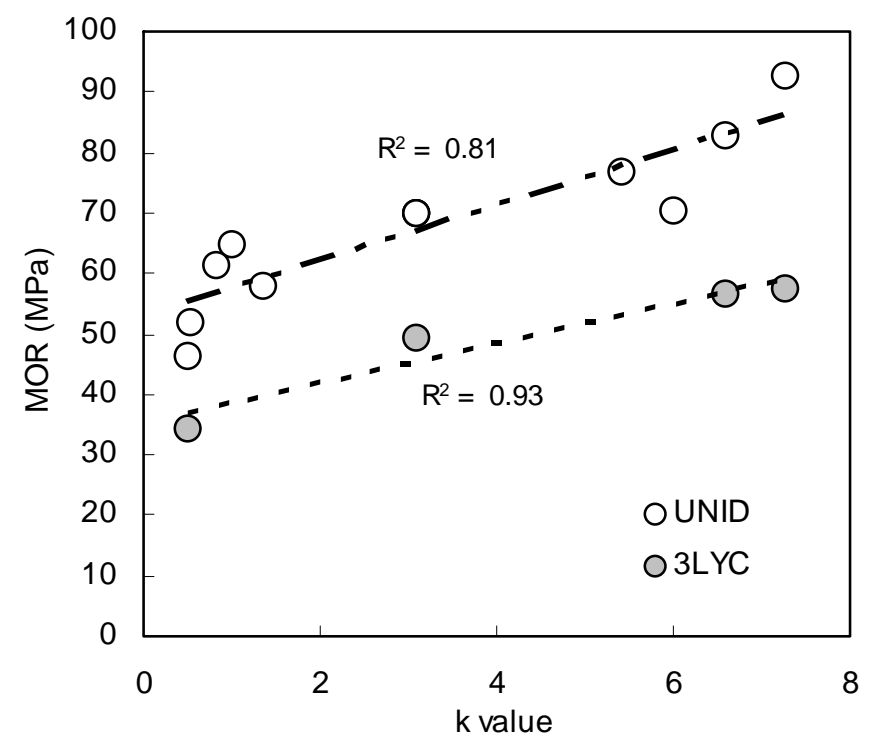




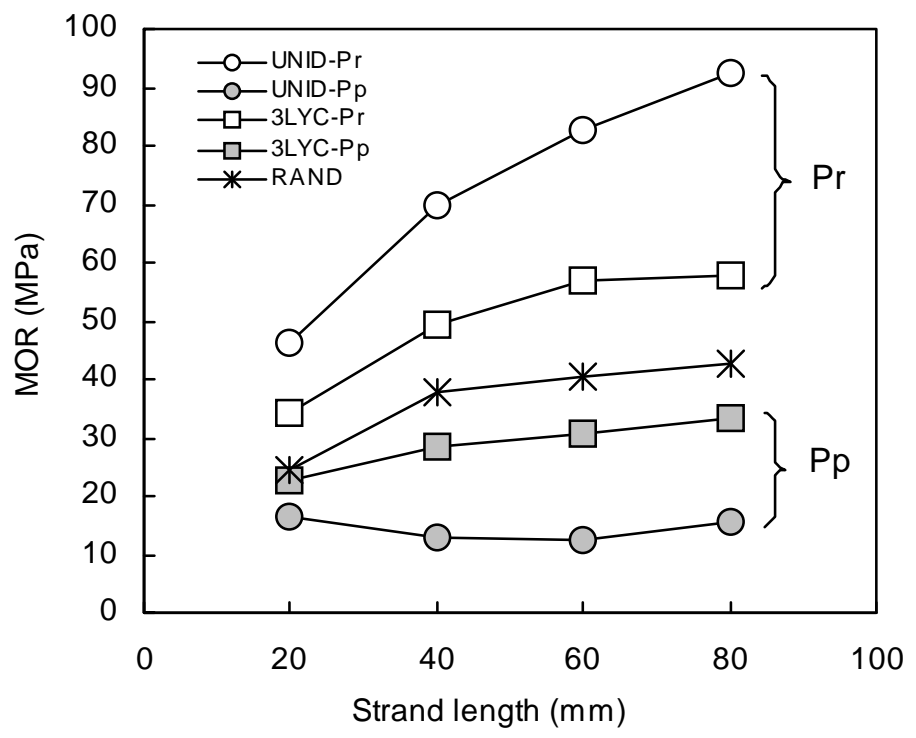




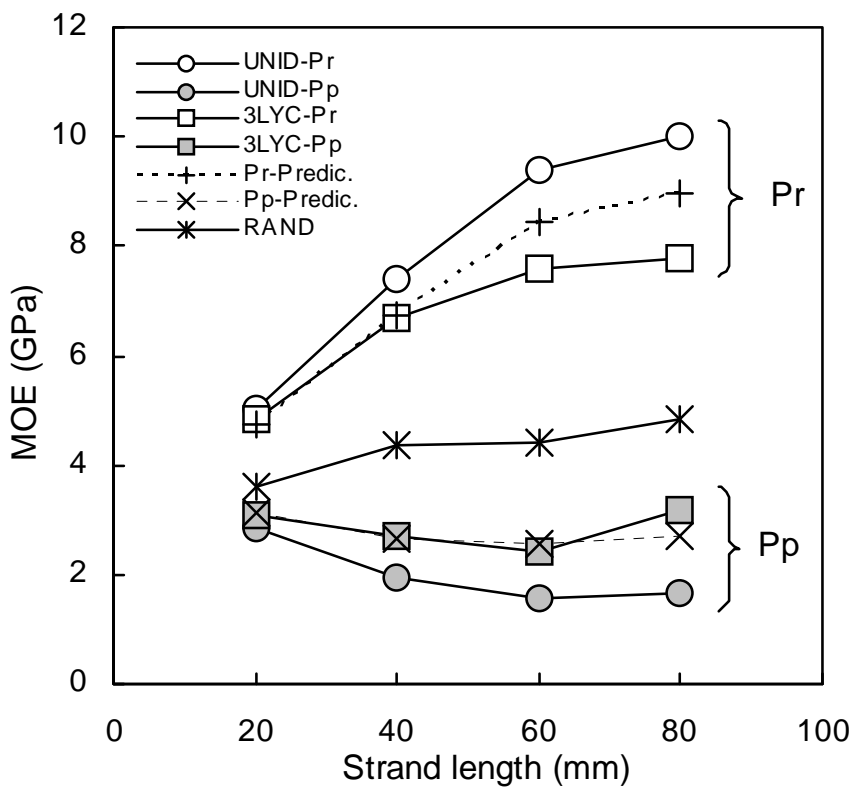




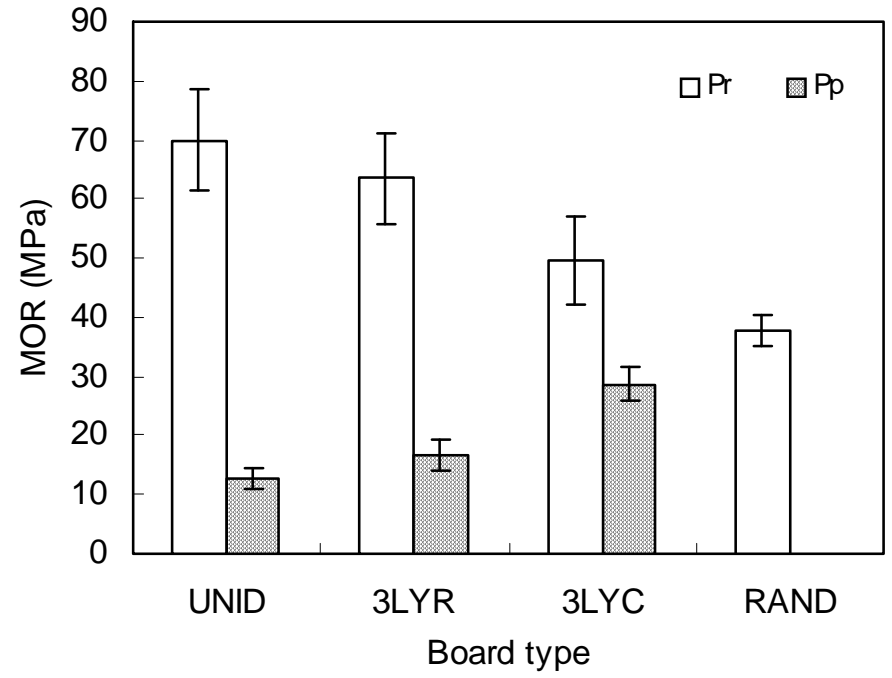




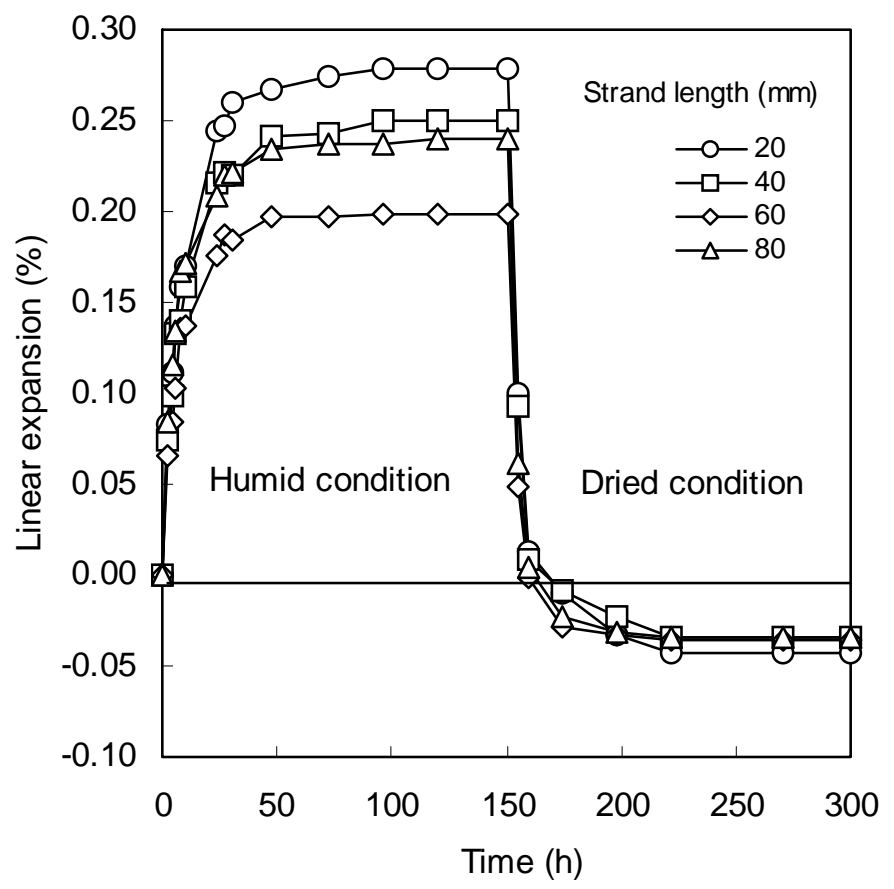

